\title{
SEBARAN DAN EFIKASI BERBAGAI GENUS CENDAWAN ENTOMOPATOGEN TERHADAP Riptortus linearis PADA KEDELAI DI LAMPUNG DAN SUMATRA SELATAN
}

\author{
Yusmani Prayogo ${ }^{1}$
}

\begin{abstract}
Distribution and efficacy on various entomopathogenic fungi at Lampung and South Sumatra as a biological control agent against Riptortus linearis. This study was conducted from June to September 2005. The fungi were isolated from insect cadavers, insect bait, and soil sample from the soybean land. Each fungal sample was identified base on their morphology using determination keys. The fungal isolates were inoculated to the pod sucking bug Riptortus linearis. The results showed that there were six genera of entomopathogenic fungi that can be isolated, i.e. Fusarium sp., Penicillium sp., Metarhizium sp., Verticillium sp., Paecilomyces sp., and Beauveria sp. The fungus-induced mortality of R. linearis varied between 5 - 30\%. Paecilomyces sp. isolated from Lebak Batang Baru induced 25\%; Beauveria sp. isolated from Pulung Kencana 25\%; Verticillium sp. isolated from Kaliungu 20\%. Metarhizium sp. isolated from Terbanggi Subing $20 \%$ and Verticillium sp. isolated from Lebak batang Baru 20\% mortality. It was suggested that these fungi have potential as biological control agents for the pod sucking bug in dry acid land.
\end{abstract}

Key words: distribution and efficacy, dry acid land, entomopathogenic fungi, soybean

\section{PENDAHULUAN}

Lahan kering masam merupakan salah satu lahan yang potensial bagi peningkatan produksi tanaman kacang-kacangan (RIPP Balitkabi, 2004). Lahan tersebut tersebar luas di Propinsi Sumatra Selatan dan Lampung dengan tingkat kesuburan yang sangat beragam. Beragamnya tingkat kesuburan juga akan menyebabkan beragam pula kendalanya. Salah satu kendala utama adalah adanya gangguan hama penyakit di samping teknik budidaya. Hasil survei terhadap jenis-jenis hama kedelai yang dilakukan oleh Tengkano et al. (2005) menunjukkan bahwa terdapat beberapa jenis hama yang dianggap sangat penting keberadaannya antara lain Riptortus linearis, Nezara viridula, dan Piezodorus hybneri. Sedangkan jenis hama yang dianggap penting antara lain Etiella zinckenella, Helicoverpa armigera, Spodoptera litura, Bemisia tabaci, Aphis glycines, dan Ophiomyia phaseoli.

Dilihat dari banyaknya jenis hama yang ada di daerah lahan kering masam, maka sebelum pengembangan tanaman kedelai di lahan tersebut sebaiknya sudah dipersiapkan teknologi pengendalian yang tepat. Hingga saat ini, pengendalian hama masih mengandalkan penggunaan insektisida kimia (Marwoto, 1992). Namun penggunaan insektisida yang tidak rasional akan menimbulkan berbagai masalah baru antara lain resistensi, resurjensi, terbunuhnya serangga non target, dan pencemaran lingkungan khususnya terhadap kesehatan manusia (Palm et al., 1970; Oka \& Bahagiawati, 1987; Vinson, 1990; Purcell \& Schrooder, 1996). Oleh karena itu, perlu dikembangkan cara pengendalian lain yang ramah lingkungan, misalnya dengan pemanfaatan agens hayati. Pemanfaatan agens hayati merupakan salah satu penerapan komponen pengendalian hama terpadu (PHT) yang harus diutamakan (Rauf, 1996).

Agens hayati yang diperoleh dari lahan setempat akan mempunyai adaptasi dan kinerja yang lebih tinggi pada hama yang akan dikendalikan dibandingkan dengan agens hayati yang diintroduksi dari daerah lain. Menurut Tengkano et al. (2005) terdapat beberapa jenis agens hayati di Lampung, yaitu kelompok predator sebanyak 24 species, parasitoid 14 spesies, dan patogen serangga (NPV) dan cendawan entomopatogen. Penggunakan cendawan entomopatogen sebagai agens hayati mempunyai prospek yang tinggi dibandingkan dengan penggunaan agens hayati lainnya (Kim et al., 2001; Cloyd, 2003; Moschetti, 2003).

Menurut Sumartini et al. (2001), cendawan entomopatogen Metarhizium anisopliae isolat Mojokerto efektif untuk mengendalikan hama

${ }^{1}$ Staf peneliti Hama dan Penyakit Balitkabi, Jl. Raya Kendalpayak KM.18, PO. BOX 66, Malang 65101 
pengisap polong kedelai. Cendawan M. anisopliae isolat Kendalpayak dilaporkan efektif untuk mengendalikan hama perusak daun kedelai Spodoptera litura (Prayogo et al., 2002). Cendawan Verticillium lecanii isolat Probolinggo efektif dapat mematikan hama pengisap polong kedelai Riptortus linearis yang sebanding dengan insektisida deltametrin (Prayogo, 2004). Selain itu, cendawan Beauveria bassiana isolat Probolinggo juga efektif dapat mengendalikan hama pengisap polong kedelai (Prayogo et al., 2004). Keefektifan cendawan - cendawan entomopatogen tersebut di atas bergantung pada asal dan jenis isolat cendawan (Prayogo et al., 2004). Penelitian ini bertujuan untuk menginventarisasi cendawan entomopatogen di lahan kering masam, terutama Propinsi Lampung dan Sumatra Selatan untuk digunakan sebagai salah satu agens hayati terhadap hama Riptortus linearis pada kedelai.

\section{METODE PENELITIAN}

Pengamatan jenis-jenis cendawan entomopatogen dilakukan dengan survei dan koleksi cendawan entomopatogen di pertanaman kedelai di Lampung dan Sumatra Selatan. Penelitian dilaksanakan pada bulan Juni sampai dengan September 2005. Metode survai yang digunakan adalah purposive random sampling. Dari setiap Kecamatan diambil sebanyak tiga desa/lokasi yang ada pertanaman kedelai sebagai unit contoh pengamatan. Dari asing-masing desa/lokasi pada hamparan tanaman kedelai diambil sebanyak 10 titik contoh secara diagonal. Contoh yang diambil yaitu serangga mati, serangga hidup, dan contoh tanah.

Contoh serangga mati diambil dari masingmasing kecamatan yang terdiri dari tiga desa yang terdapat tanaman kedelai. Setiap desa diambil sebanyak 10 titik contoh yang ditentukan secara diagonal, sedangkan setiap titik contoh diambil minimal sebanyak 10 ekor. Contoh serangga hidup yang diambil adalah $R$. linearis dan Spodoptera litura masing-masing lokasi 10 ekor per titik contoh kemudian dipelihara dan diberi pakan secukupnya. Contoh tanah diambil dari kedalaman $5 \mathrm{~cm}$ sebanyak 100 g per titik contoh, kemudian masing-masing contoh dari lapangan dimasukkan ke dalam cawan petri steril dan disimpan di dalam kantong plastik. Masing-masing contoh dibawa ke laboratorium Balitkabi Malang, kemudian dilakukan isolasi cendawan entomopatogen dan uji keefektifannya terhadap $R$. linearis.

Isolasi cendawan entomopatogen dari serangga mati. Serangga hama mati $R$. linearis dan $S$. litura yang terinfeksi cendawan entomopatogen dari lapangan dibawa ke laboratorium. Tubuh serangga dipotong-potong dengan ukuran $\pm 0,5 \mathrm{~cm}$, kemudian direndam dengan larutan klorok 0,25\% selama 30 detik untuk mematikan cendawan kontaminan, selanjutnya direndam di dalam air steril kemudian dikeringkan dengan kertas saring dan ditumbuhkan pada medium potato dextrose agar (PDA) atau medium selektif (soybean dextrose yeast agar). Setelah koloni cendawan berumur 7 hari dilakukan pengamatan secara mikroskopis dan cendawan diidentifikasi berdasarkan karakteristik morfologinya menggunakan kunci determinasi yang dikembangkan oleh Samson et al. (1988).

Isolasi cendawan entomopatogen dengan pengumpanan (trapping). Serangga hidup $R$. linearis dan S. litura yang diambil dari lapangan dipaparkan pada contoh tanah di dalam cawan petri, selanjutnya dibawa ke laboratorium dan dimasukkan ke dalam inkubator sampai serangga mati. Setelah itu, bangkai serangga dipotong-potong $0,5 \mathrm{~cm}$, kemudian direndam dalam larutan klorok 0,25\% selama 30 detik untuk mematikan cendawan kontaminan. Selanjutnya, potongan tubuh serangga direndam dalam air steril selama 60 detik, kemudian dikeringkan dengan kertas saring dan selanjutnya ditumbuhkan pada medium PDA. Setelah terbentuk koloni cendawan pada umur 7 hari dilakukan pengamatan secara mikroskopis dan cendawan diidentifikasi berdasarkan karakteristik morfologinya menggunakan kunci determinasi yang dikembangkan oleh Samson et al. (1988).

Isolasi cendawan entomopatogen dari tanah. Tanah yang diambil dari sekitar lahan pertanaman kedelai ditimbang $1 \mathrm{~g}$ dan dilarutkan dengan $9 \mathrm{ml}$ air dalam tabung reaksi. Setelah itu, dengan mikro pipet diambil $1 \mathrm{ml}$ kemudian dibuat seri pengenceran bertingkat hingga $10^{-4}$. Dari masing-masing seri pengenceran diambil $1 \mathrm{ml}$ untuk dimasukkan ke dalam cawan petri steril yang diisi media PDA $10 \mathrm{ml}$. Setelah koloni cendawan terbentuk pada umur 7 hari dilakukan pengamatan secara mikroskopis dan cendawan diidentifikasi berdasarkan karakteristik morfologinya menggunakan kunci determinasi yang dikembangkan Samson et al. (1988) 
Uji keefektifan cendawan entomopatogen. Semua isolat cendawan entomopatogen yang sudah diidentifikasi kemudian diuji keefektifannya terhadap hama pengisap polong kedelai $R$. linearis (nimfa instar II). Serangga uji dimasukkan ke dalam milar plastik berdiameter $10 \mathrm{~cm}$ dan tinggi $25 \mathrm{~cm}$, setiap milar berisi 25 ekor dan masing-masing perlakuan jenis cendawan diulang 4 kali untuk masing-masing perlakuan jenis cendawan. Setiap jenis cendawan entomopatogen diperbanyak pada medium PDA. Setelah berumur 30 hari (30 HSI), konidia cendawan dipanen. Biakan cendawan di dalam cawan petri yang siap dipanen ditambah air kemudian koloninya dikerok dengan kuas halus, setelah itu dimasukkan ke dalam tabung reaksi dan dikocok dengan shaker selama 60 detik. Setelah itu, mengambil suspensi konidia dengan pipet dan diteteskan pada permukaan haemocytometer kemudian ditutup cover glass. Selanjutnya, jumlah konidia dihitung di bawah mikroskop stereo dengan pembesaran 400x hingga memperoleh kerapatan konidia $10^{7} / \mathrm{ml}$. Aplikasi cendawan dilakukan dengan cara disemprotkan pada seluruh permukaaan tubuh serangga sebanyak $20 \mathrm{ml} / 25$ ekor $R$. linearis. Setiap hari serangga uji diberi pakan kacang panjang secukupnya. Keefektifan cendawan dihitung berdasarkan mortalitas $R$. linearis kumulatif hingga 14 hari setelah aplikasi (HSA).

\section{HASIL DAN PEMBAHASAN}

Isolat - isolat Cendawan Entomopatogen yang Ditemukan Di Propinsi Lampung dan Sumatra Selatan. Pengamatan cendawan entomopatogen di Propinsi Lampung dan Sumatra Selatan yang telah dilakukan meliputi 7 kabupaten, 24 kecamatan, dan 39 desa. Hasil pengamatan menunjukkan bahwa dari Propinsi Lampung diperoleh enam jenis isolat cendawan entomopatogen antara lain Fusarium sp., Penicillium sp., Metarhizium sp., Verticillium sp., Paecilomyces sp., dan Beauveria sp. (Tabel 1). Cendawan-cendawan tersebut dapat ditemukan dari berbagai metode isolasi. Cendawan yang diperoleh dari isolasi bangkai S. litura yaitu Metarhizium sp. dan Penicillium sp., sedangkan dari metode trapping diperoleh Fusarium sp., Penicillium sp., Paecilomyces sp., dan Beauveria sp. Hanya satu isolat cendawan entomopatogen yang berhasil diisolasi dari tanah, yaitu Verticillium sp.

Dari Propinsi Lampung diperoleh tiga isolat cendawan Fusarium sp. yaitu dari desa Gunung Sugih, Sidomulyo, dan Pulung Kencana. Cendawan
Penicillium sp. diperoleh dari Gunung Sugih dan Terbanggi Subing. Cendawan Metarhizium sp. diperoleh dari Terbanggi Subing. Cendawan Verticillium sp. diperoleh dari Kaliungu. Selanjutnya, cendawan Paecilomyces sp. dan Beauveria sp. masing-masing diperoleh dari Kaliungu dan Pulung Kencana.

Di Propinsi Sumatra Selatan, diperoleh empat isolat cendawan yaitu Penicillium sp., Fusarium sp., Paecilomyces sp., dan Verticillium sp. (Tabel 2). Cendawan entomopatogen Penicillium sp., Fusarium sp., dan Paecilomyces sp. diperoleh dengan metode isolasi trapping, sedangkan cendawan Verticillium sp. diperoleh dari metode isolasi tanah. Cendawan Metarhizium sp. dan Penicillium sp. diisolasi dari bangkai ulat grayak (S. litura). Cendawan Penicillium sp. diperoleh dari Tanjung Seteko dan Gelumbang (Agrotek). Cendawan Fusarium sp. diperoleh dari Tanjung Seteko, Gelumbang (Agrotek), dan Kepur. Selanjutnya, Paecilomyces sp. diperoleh dari Kepur dan Lebak Batang Baru, sedangkan cendawan Verticillium sp. diperoleh dari Lebak Batang Baru.

Cendawan entomopatogen Verticillium sp., Paecilomyces sp., Metarhizium sp., dan Beauveria sp. banyak digunakan sebagai agens hayati pada tanaman sayuran maupun perkebunan. Cendawan Fusarium spp. juga pernah diperoleh dari ulat api yang menyerang tanaman teh di Jawa Barat (Widayat \& Rayati, 1993). Prayogo et al. (2002) mendapatkan Fusarium sp. dan Penicillium sp. yang menginfeksi ulat grayak pada tanaman kedelai di Jawa Timur.

Cendawan Fusarium sp. mempunyai inang yang luas, di samping sebagai patogen tanaman juga bersifat patogenik terhadap beberapa jenis serangga hama (Teetor-Barsch \& Roberts, 1983). F. solani mampu menyebabkan kematian pada larva maupun serangga dewasa bark beetles Scolytus scolytus (Coleoptera: Scolytidae) (Barson, 1976). Cendawan tersebut menghasilkan senyawa metabolit yang disebut fusaric acid dan pigmen naphthazarin yang berfungsi sebagai insektisida (Claydon et al., 1977). Cendawan Penicillium sp. menghasilkan beberapa jenis toksin antara lain ochratoxin A, brevianamide A, penicillic acid, dan citrinin yang menyebabkan kematian pada larva Drosophila melanogaster dan Spodoptera littoralis (Paterson et al., 1987).

Cendawan Verticillium sp. dan Paecilomyces spp. banyak ditemukan menginfeksi kutu daun jagung Rhopalosiphum maidis dan ulat kubis Plutella xylostella di daerah Bogor yang mempunyai kelembaban tinggi. Prayogo et al. (2002) 
Tabel 1. Isolat cendawan entomopatogen di lahan kering masam, Lampung

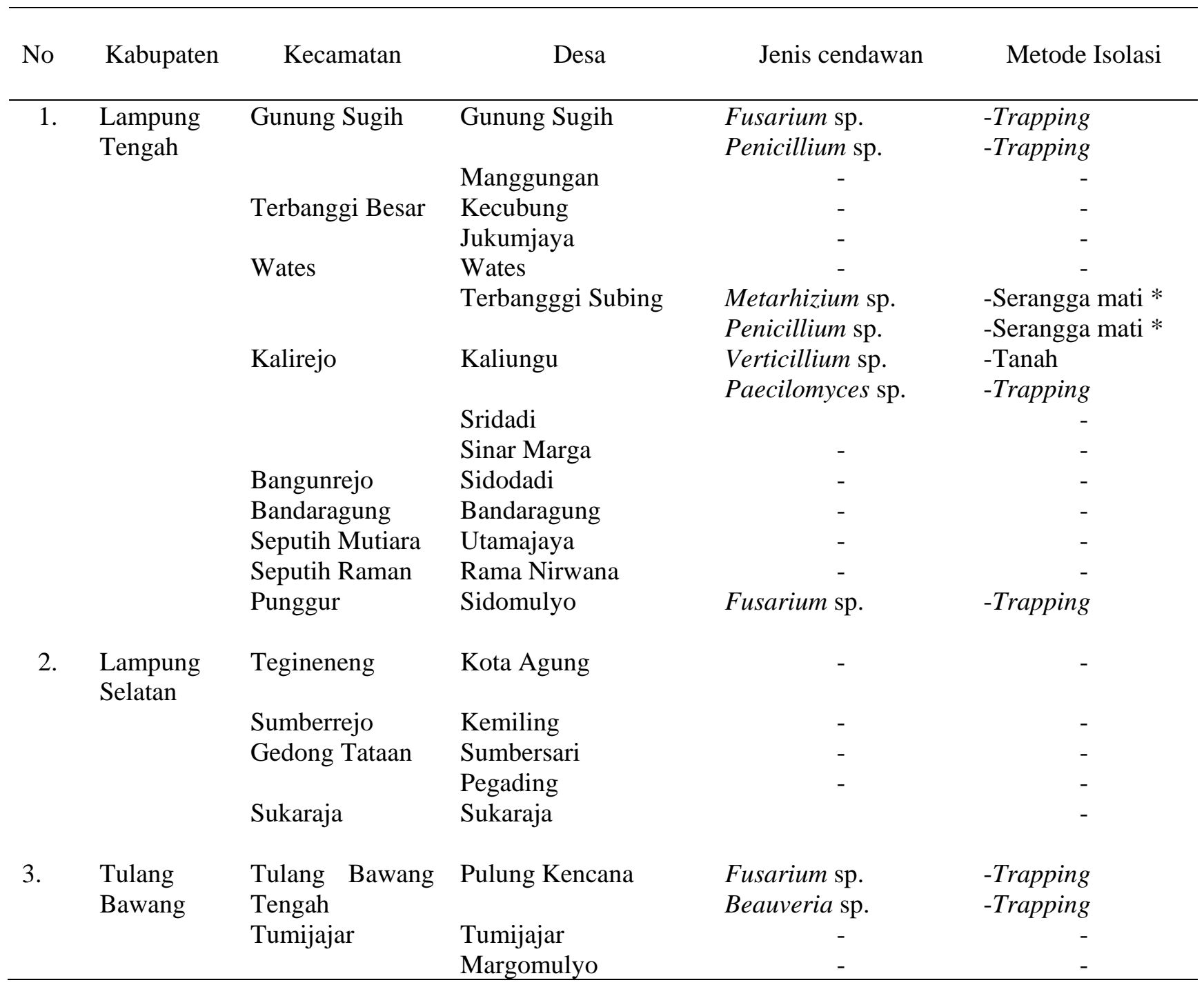

*) Bangkai S. litura

mendapatkan cendawan V. lecanii di Jawa Timur yang menginfeksi beberapa jenis hama termasuk walang sangit Leptocorisa acuta. Hal ini mengindikasikan bahwa cendawan Verticillim spp. dan Paecilomyces spp. mempunyai kisaran inang yang luas.

Hasil penelitian ini menginformasikan bahwa di Propinsi Sumatra Selatan dan Lampung sudah tersedia cendawan entomopatogen sebagai agens hayati lokal yang sangat beragam jenisnya. Kenyataan di lapangan menunjukkan bahwa berdasarkan pengamatan, peran dan kinerja agens hayati tersebut belum optimal dalam menekan populasi hama. Oleh karena itu, masih diperlukan serangkaian penelitian lanjutan untuk mengkaji lebih lanjut upaya peningkatkan keefektifan kinerja musuh alami tersebut.

\section{Uji Keefektifan Cendawan Entomopatogen terhadap Hama Pengisap Polong Kedelai R. linearis.}

Beberapa jenis cendawan entomopatogen yang sudah diidentifikasi kemudian diaplikasikan pada hama pengisap polong kedelai $R$. linearis. Hasil pengamatan menunjukkan bahwa mortalitas serangga uji bervariasi, bergantung pada jenis isolat maupun asal isolat. Cendawan entomopatogen yang diuji menyebabkan mortalitas $R$. linearis dengan kisaran 
Tabel 2. Isolat cendawan entomopatogen di lahan kering masam, Sumatra Selatan

\begin{tabular}{|c|c|c|c|c|c|}
\hline No & Kabupaten & Kecamatan & Desa & Jenis cendawan & Metode Isolasi \\
\hline \multirow[t]{2}{*}{1.} & OI & Indralaya & Tanjung Seteko & $\begin{array}{l}\text { Penicillium sp. } \\
\text { Fusarium sp. }\end{array}$ & $\begin{array}{l}\text {-Trapping } \\
\text {-Trapping }\end{array}$ \\
\hline & & & UI Kumahang & - & - \\
\hline \multirow[t]{7}{*}{2.} & Muara Enim & Gelumbang & $\begin{array}{l}\text { Gelumbang } \\
\text { (Agrotek) }\end{array}$ & $\begin{array}{l}\text { Fusarium sp. } \\
\text { Penicillium sp. }\end{array}$ & $\begin{array}{l}\text {-Trapping } \\
\text {-Trapping }\end{array}$ \\
\hline & & Gelumbang & Talang Taling & - & - \\
\hline & & & Gelumbang & - & - \\
\hline & & & Kepur & $\begin{array}{l}\text { Paecilomyces sp. } \\
\text { Fusarium sp. }\end{array}$ & $\begin{array}{l}\text {-Trapping } \\
\text {-Trapping }\end{array}$ \\
\hline & & Lebak & Lebak & - & - \\
\hline & & RB Lubay & Bringin & - & - \\
\hline & & & Karang Agung & - & - \\
\hline \multirow[t]{2}{*}{3.} & OKU & Baturaja & Gunung Meraksa & - & - \\
\hline & & Lebak batang & Lebak Batang Baru & $\begin{array}{l}\text { Paecilomyces sp. } \\
\text { Verticillium sp. }\end{array}$ & $\begin{array}{l}\text { - Trapping } \\
\text { - Tanah }\end{array}$ \\
\hline \multirow[t]{5}{*}{4.} & OKI & Kayu Agung & Buluh Cawang & - & - \\
\hline & & Padamaran & Srinanti & - & - \\
\hline & & & Sukaraja & - & - \\
\hline & & & Lengkuwijaya & - & - \\
\hline & & Lempuing & Sialang Barat & - & - \\
\hline
\end{tabular}

5 - 30\% (Tabel 3). Keefektifan cendawan paling tinggi ditunjukkan oleh cendawan Paecilomyces spp. isolat Lebak Batang Baru yang mampu menyebabkan mortalitas $R$. linearis sampai $30 \%$. Cendawan Paecilomyces sp. isolat Kaliungu mampu menyebabkan mortalitas $R$. linearis sebesar $25 \%$. Namun, Paecilomyces sp. isolat Kepur hanya menyebabkan mortalitas serangga uji 8\%. Kenyataan ini mengindikasikan bahwa keefektifan cendawan entomopatogen dipengaruhi oleh asal isolat diperoleh. Menurut Prayogo (2004), cendawan Paecilomyces fumosoroseus merupakan salah satu cendawan yang cukup efektif untuk mengendalikan hama pengisap polong kedelai $R$. linearis terutama pada stadia telur. Telur $R$. linearis yang terinfeksi cendawan $P$. fumosoroseus umumnya tidak mampu menetas. Dilaporkan lebih lanjut bahwa, telur $R$. linearis yang berhasil menetas menjadi nimfa instar I selanjutnya tidak dapat bermetamorfosis menjadi nimfa instar II. Hal ini disebabkan cendawan sudah menginfeksi jaringan tubuh serangga, namun serangga belum mengalami kematian atau cendawan mengalami fase lag (Cloyd, 2003). Fase lag yang dialami cendawan entomopatogen biasanya terjadi apabila lingkungan kurang menguntungkan (Cagan \& Svercel, 2001). Oleh karena itu, pengendalian biologis biasanya membutuhkan waktu lebih lama dibandingkan dengan pestisida sintesis (Novizan, 2002).

Pada Tabel 3, terlihat bahwa cendawan Beauveria sp. isolat Pulung Kencana mampu menyebabkan mortalitas $R$. linearis sebesar 25\%. Dilaporkan oleh Prayogo et al. (2004) bahwa cendawan $B$. bassiana isolat Probolinggo cukup efektif untuk mengendalikan hama pengisap polong kacang-kacangan. Bahkan hingga kini cendawan entomopatogen tersebut sudah dapat dikomersialkan untuk mengendalikan berbagai jenis hama utama tanaman sayuran maupun perkebunan (Widayat \& Rayati, 1993; Junianto, 2000; Ambetghar, 2003; Moschetti, 2003).

Isolat cendawan Verticillium sp. yang diperoleh dari Lebak Batang Baru mampu menyebabkan mortalitas R. linearis 20\%. Menurut Prayogo (2004), 
Tabel 3. Keefektifan beberapa jenis cendawan entomopatogen isolat lahan kering masam terhadap nimfa II $R$. linearis

\begin{tabular}{lllc}
\hline No. & $\begin{array}{l}\text { Jenis cendawan } \\
\text { entomopatogen }\end{array}$ & \multicolumn{1}{c}{ Asal isolat } & Mortalitas R. linearis (\%) \\
\hline 1. & Penicillium spp. & Gunung Sugih (Lampung) & 5 \\
& & Terbanggi Subing (Lampung) & 11 \\
& & Tanjung Seteko (Sumatra Selatan) & 9 \\
& & Gelumbang (Agrotek) (Sumatra Selatan) & 9 \\
2. & Fusarium spp. & Gunung Sugih (Lampung) & 10 \\
& & Sidomulyo (Lampung) & 9 \\
& & Pulung Kencana (lampung) & 5 \\
& & Tanjung Seteko (Sumatra Selatan) & 8 \\
& & Gelumbang (Agrotek) (Sumatra Selatan) & 8 \\
& & Kepur (Sumatra Selatan) & 9 \\
3. & Paecilomyces spp. & Kaliungu (Lampung) & 25 \\
& & Kepur (Sumatra Selatan) & 8 \\
& & Lebak Batang Baru (Sumatra Selatan) & 30 \\
4. & Metarhizium spp. & Terbagi Subing (Lampung) & 20 \\
5. & Verticillium spp. & Kaliungu (Lampung) & 20 \\
& & Lebak Batang Baru (Sumatra Selatan) & 20 \\
6. & Beauveria spp. & Pulung Kencana (Lampung) & 25 \\
\hline
\end{tabular}

cendawan Verticillium lecanii merupakan salah satu jenis cendawan yang dikatakan paling efektif untuk mengendalikan hama pengisap polong kedelai. Keefektifan terlihat dari mortalitas imago $R$. linearis hingga mencapai $81 \%$. Keefektifan cendawan juga terlihat dari kerusakan polong yang setara dengan akibat aplikasi insektisida deltametrin. Selain efektif terhadap $R$. linearis, $V$. lecanii juga efektif untuk mengendalikan kutu daun (Hall, 1981). Selanjutnya Cloyd (2003) juga melaporkan bahwa cendawan $V$. lecanii merupakan salah satu agens hayati yang efektif untuk mengendalikan hama pengisap polong kacang-kacangan.

Hasil penelitian ini menginformasikan bahwa di lahan kering masam di Lampung dan Sumatra Selatan sudah terdapat berbagai isolat cendawan entomopatogen yang cukup beragam. Setiap isolat cendawan entomopatogen mempunyai inang yang berbeda-beda. Oleh karena itu, keberadaan cendawan tersebut masih membuka peluang yang tinggi untuk dapat ditingkatkan keefektifannya, misalnya dengan menumbuhkan isolat tersebut pada berbagai jenis medium buatan (Susilo et al., 1993; Prayogo \& Tengkano, 2005) atau menambahkan minyak nabati sebagai adjuvant (Devi \& Prasad, 1988; Leland, 2001a; 2001b).

\section{SIMPULAN DAN SARAN}

Berdasarkan hasil penelitian ini dapat disimpulkan hal-hal sebagai berikut. Cendawan entomopatogen yang ada di lahan kering masam di Propinsi Lampung dan Sumatra Selatan cukup beragam antara lain Fusarium sp., Penicillium sp., Paecilomyces sp., Verticillium sp., Metarhizium sp., dan Beauveria sp. Ada enam isolat cendawan entomopatogen yang mampu menginfeksi $R$. linearis, yaitu Paecilomyces sp. isolat Lebak Batang Baru dan Kaliungu, Verticillium sp., isolat Lebak batang Baru dan Kaliungu, Metarhizium sp. isolat Terbanggi Subing, dan Beauveria sp. isolat Pulung Kencana. 


\section{SANWACANA}

Pada kesempatan ini penulis mengucapkan banyak terimakasih kepada Ketua Kelti Proteksi Balitkabi Dr. Ir. Suharsono, MS; Kepala Balitkabi Prof. Riset. Dr. Subandi, dan Ketua PEKI Prof. Riset. Dr. Titis Adisarwanto, atas saran dan koreksi naskah ini.

\section{DAFTAR PUSTAKA}

Ambetghar, V. 2003. Beauveria bassiana. Biological insecticide.http://www.nipm.in/Beauveria\%20 bassiana.htm [26 Mei 2005].

Barson, G. 1976. Fusarium solani, a weak pathogen of the larval stages of the large elm bark beetle Scolytus scolytus (Coleoptera: Scolytidae). J Invertebr Pathol. (27):307-309.

Cagan \& M. Svercel. 2001. The influence of ultraviolet light on pathogenicity of entomopathogenic fungus Beauveria bassiana (balsamo) Vuillemin the european corn borer Ostrinia nubilalis HBN (Lepidoptera: Cerambidae).http://www.agr.hr/jcea/issues/jce a235/jcea2349.html [21 Juli 2005].

Claydon, N., J.F. Grove \& M. Pople. 1977. Insecticidal secondary metabolic products from the entomogenous fungus Fusarium solani. J Inveretbr Pathol. (30):216-223.

Cloyd, R. 2003. The entomopathogen Verticillium lecanii. Midwest Biological Control News. University of Illinois. http: // www. extension. umn.Edu / distribution /horticulture/ DG7373. html [12 Februari 2005].

Devi, P.S.V \& Y.G. Prasad. 1988. Compatibility of oils and antifeedants of plant origin with the entomopathogenic fungus Nomuraea rileyi. J Invertebr Pathol (68):91-93.

Hall, R.A. 1981. The fungus Verticillium lecanii as a microbial insecticide against aphids and scales. p.483-498. In: Microbial control of pests and plant diseases. London: Academic Press.
Junianto, Y.D. 2000. Penggunaan Beauveria bassiana untuk pengendalian hama tanaman kopi dan kakao. Makalah Workshop Nasional Pengendalian Hayati OPT Tanaman Perkebunan. Cipayung, 15-17 Februari 2000.

Kim, J.J., M.H. Lee, C.S. Yoon, H.S. Kim, \& J.K. You. 2001. Control of cotton aphid and greenhouse whitefly with a fungal pathogen. Food \& Fertilizer Technology Center An International Information Center for Farmers in The Asia Pacific Region. http: // www. agnet. org/ library/ article/ eb 502. htm [27Desember 2004].

Leland, J.E. 2001a. Enviromental - stress tolerant formulations of Metarhizium anisopliae var. acridum for control of African Desert locust (Schistocerca gregaria). Disertation. Virginia: Faculty of Virginia Polytechnic. http://scholar.lib.vt.edu/theses/available/etd_1 2052001_115455/unrestrictited/Jleland Dissertation.PDF. [21 Juli 2005].

Leland, J.E. 2001b. Coating Metarhizium anisopliae var Acridum with water soluble lignins for enhaced UVB-protection and effects on virulence to Schistocerca Americana (Drary). Virginia: Department of Entomology. http://essa.confex.com/esa/2001/echprogram/ paper3552.htm [21 Juli 2005].

Marwoto. 1992. Masalah pengendalian hama kedelai di tingkat petani. hlm 37-43. Dalam: Marwoto, N. Saleh, Sunardi, \& A. Winarto (Editor.). Risalah Lokakarya Pengendalian Hama Terpadu Tanaman Kedelai. Malang 810 Agustus 1991. Balittan Malang.

Moschetti, R. 2003. Microbial insecticide Beauveria bassiana. Integrated Pest Management Bulletin. http://www.IPM of Alaska. Homestead. com /files/beauveria.html [22 Mei 2005].

Novizan. 2002. Membuat dan memanfaatkan pestisida ramah lingkungan. Agromedia Pustaka Jakarta. 
Oka, I.N \& A.H. Bahagiawati. 1987. Konsepsi pengendalian terpadu hama menjamin kelestarian swasembada pangan dan lingkungan. Makalah Seminar Ilmiah Jubileum Perak Universitas Udayana. Denpasar, 21-25 September 1987.

Palm, C.E., W.W. Dykstra, G. Ferguson, E. Hansberry, W.Y. Hayes, J.R.L.W. Hazleton, J.C. Horstall, E.K. Knipling, L.D. Leach, L.R. Lovvorn \& G.A. Swanson. 1970. Insect Pest Management and Control. Principles of plant \& animal pest control. (3).

Paterson, R.R..M., M.S.J. Simmonds \& W.M. Blaney. 1987. Mycopesticidal effects of characterized extracts of Penicillium isolates and purified secondary metabolites (including mycotoxins) on Drosophila melanogaster and Spodoptera littoralis. J Invertebr Pathol. (50):124-133.

Prayogo, Y., W. Tengkano \& Suharsono. 2002. Jamur entomopatogen pada Spodptera litura dan Helicoverpa armigera. Prosiding Seminar Teknologi Inovatif Tanaman Kacangkacangan dan Umbi-umbian Mendukung Ketahanan Pangan Balitkabi. Malang. 25-26 Juli 2002. hlm:132-144.

Prayogo, Y. 2004. Keefektifan lima jenis cendawan entomopatogen terhadap hama pengisap polong kedelai Riptortus linearis (Hemiptera: Alydidae) dan dampaknya terhadap predator Oxyopes javanus Thorell (Araneida: Oxyopidae). Tesis. Sekolah Pascasarjana. Departemen Hama dan Penyakit Tanaman. Institut Pertanian Bogor.

Prayogo, Y., W. Tengkano \& Suharsono. 2004. Potensi cendawan Beauveria bassiana isolat Probolinggo untuk mengendalikan hama pengisap polong kedelai (Riptortus linearis). hlm:95-99. Dalam: Nganro, N., C. Sugandawati, M. Zairin, A. Basukriadi, A. Tahir, P. Sukardi, I. Sulistyo, T. Hardiyati, E. Yuwono, Y. Sistina \& H. Winarsi (Editor). Majalah Ilmiah Biologi BIOSFERA. Universitas Jenderal Sudirman, Purwokerto. Vol.21(3).
Prayogo, Y \& W. Tengkano. 2005. Pengaruh media tumbuh terhadap daya berkecambah, sporulasi, dan virulensi Metarhizium anisopliae (Metchnikoff) Sorokin isolat Kendalpayak pada larva Spodoptera litura. Hlm:123-131. Dalam: Bintoro, P., Umiyati, P. Widiyaningrum \& I. O. Utami (Editor). Jurnal Pengembangan Ilmu-ilmu Pertanian SAINTEKS. Vol. XI(3).

Purcell, M.F \& W.J. Schrooder. 1996. Effect of silwet L-77 and diazinon on three tephritid fruit flies (Diptera: Tephritidae) and associated endoparasitoids. J Econ Entomol (89):15661570 .

Rauf, A. 1996. Analisis ekosistem dalam pengendalian hama terpadu. Makalah Pelatihan peramalan hama dan penyakit tanaman padi dan palawija tingkat nasional. Jatisari, 2-9 Januari 1996.

RIPP BALITKBI. 2004. Rencana Induk Program Penelitian Balai Penelitian Tanaman Kacangkacangan dan Umbi-umbian. Bahan diskusi yang disampaikan pada Rapat Kerja Pusat Penelitian dan Pengembangan Tanaman Pangan. Batu, 22-24 September 2004.

Samson, R.A., H.C.Evans \& J.P.Latge. 1988. Atlas of entomopathogenic fungi. Prinejerverlag Berlin Heodelberg, New York. London. Tokyo.

Sumartini, Y. Prayogo, S. W. Indiati \& S. Hardaningsih. 2001. Pemanfaatan jamur Metarhizium anisopliae untuk pengendalian pengisap polong (Riptortus linearis) pada kedelai. Hlm:54-157. Dalam: Baehaki, S.E., E. Santosa, Hendarsih, T. Suryana, N. Widiarta, dan Sukirno (Editor). Prosiding Simposium Pengendalian Hayati Serangga. Balitpa Sukamandi. Sukamandi, 14-15 Maret 2001.

Susilo, A., S. Santoso \& Tutung H.A. 1993. Sporulasi, viabilitas cendawan Metarhizium anisopliae (Metscnikoff) Sorokin. Pada media jagung dan patogenistasnya terhadap larva Oryctes rhinoceros. hlm: 104-112. Dalam: Martono E., E. Mahrub, N.S. Putra, dan Y. Trisetyawati (Editor). Prosiding Simposium 
Patologi Serangga I. Universitas Gadjahmada. Yogyakarta, 12-13 Oktober 1993.

Tengkano, W., Supriyatin, Suharsono, Bedjo, Y. Prayogo \& Purwantoro. 2005. Status hama kedelai dan musuh alaminya di lahan kering masam Propinsi Lampung. Makalah disampaikan pada Lokakarya dan Seminar Nasional Peningkatan Produksi Kacangkacangan dan Umbi-umbian Mendukung Kemandirian Pangan. Malang, 26-27 Juli 2005. [belum terbit].

Teetor-Barsch, G.H \& D.W. Roberts. 1983. Entomogenous Fusarium species. Mycopathology. (84):3-16.
Vinson, S.B. 1990. Potential impact of microbial insecticides on beneficial arthropods in the terrestrial environment. pp:43-64. In: Laird, M., L.A. Lacey, E.W. Davidson (Eds.). Safety of Microbial Insecticides. CRC Press, Boca Raton. FL, USA.

Widayat, W \& D.J. Rayati. 1993. Hasil penelitian jamur entomopatogenik lokal dan prospek penggunaannya sebagai insektisida hayati. hlm 61-74. Dalam: Martono E., E. Mahrub, N.S. Putra, dan Y. Trisetyawati (Editor.). Prosiding Simposium Patologi Serangga I. Universitas Gadjahmada. Yogyakarta, 12-13 Oktober 1993. 